\title{
Article \\ Control of the Redox Potential by Microcontroller Technology: Researching the Leaching of Chalcopyrite
}

\author{
Xin Sun (D), Wenbing Yuan, Kai Jin and Yansheng Zhang * \\ School of Minerals Processing and Bioengineering, Central South University, Changsha 410083, China; \\ 185611047@csu.edu.cn (X.S.); 205612133@csu.edu.cn (W.Y.); jk13689295605@163.com (K.J.) \\ * Correspondence: Zhangyansheng405@126.com
}

Citation: Sun, X.; Yuan, W.; Jin, K.; Zhang, Y. Control of the Redox Potential by Microcontroller Technology: Researching the Leaching of Chalcopyrite. Minerals 2021, 11, 382. https://doi.org/ $10.3390 / \min 11040382$

Academic Editor: Kenneth N. Han

Received: 9 March 2021

Accepted: 30 March 2021

Published: 2 April 2021

Publisher's Note: MDPI stays neutral with regard to jurisdictional claims in published maps and institutional affiliations.

Copyright: (c) 2021 by the authors. Licensee MDPI, Basel, Switzerland. This article is an open access article distributed under the terms and conditions of the Creative Commons Attribution (CC BY) license (https:// creativecommons.org/licenses/by/ $4.0 /)$.

\begin{abstract}
The leaching of chalcopyrite under different redox potentials was studied with a redox potential controlling device based on microcontroller technology. The leaching test was carried out in a $500 \mathrm{~mL}$ flask with $4 \mathrm{~g}$ pure chalcopyrite and $200 \mathrm{~mL}$ sulfuric acid. The additional total Fe concentration was $0.1 \mathrm{~mol} / \mathrm{kg}$, and the initial $\mathrm{pH}$ was 0.7 . Chalcopyrite leaching tests with initial redox potential of $400 \mathrm{mV}$ and $600 \mathrm{mV}$ (vs. $\mathrm{Ag} / \mathrm{AgCl}$, the same below) and controlled redox potential of $350 \mathrm{mV}, 400 \mathrm{mV}, 450 \mathrm{mV}, 500 \mathrm{mV}$, and $600 \mathrm{mV}$ were carried out at a temperature of $60{ }^{\circ} \mathrm{C}$ and a stirring speed of $300 \mathrm{rpm}$. The results showed that the dissolution of chalcopyrite could not be hindered until the granular intermediates $\left(\mathrm{S}^{0}\right.$ and $\left.\mathrm{S}_{\mathrm{n}}{ }^{2-}\right)$ accumulated to a certain amount on the chalcopyrite surface. The main passivating species in chalcopyrite dissolution may be iron-deficient polysulfides. At $400 \mathrm{mV}$, the chalcopyrite passivation by polysulfides was overcome by the galvanic effect between pyrite and chalcopyrite, and the chalcopyrite was rapidly oxidized with $\mathrm{Cu}$ leaching rate reaching up to $32 \%$ in $7 \mathrm{~h}$, while it was only $15 \%$ in the other experimental groups. However, at $450-500 \mathrm{mV}$, pyrite was oxidized and the galvanic effect between chalcopyrite and pyrite was destroyed, leading to a significant decrease in $\mathrm{Cu}$ leaching rate. When the redox potential was $600 \mathrm{mV}$, the dissolution of metal-deficient polysulfides was promoted; thus, the passivation was weakened.
\end{abstract}

Keywords: redox potential control; chalcopyrite; microcontroller; iron-deficient polysulfides

\section{Introduction}

Chalcopyrite $\left(\mathrm{CuFeS}_{2}\right)$ is the most abundant copper-bearing mineral in the earth's crust, accounting for more than $70 \%$ of the global copper reserves [1]. The processes to extract copper from chalcopyrite include flotation, pyrometallurgy, and electrorefining. However, with the development of chemical and biological leaching for sulfide ores, hydrometallurgy has gradually become a promising technology to extract copper directly from low-grade ores and flotation concentrates. Compared with traditional processes, hydrometallurgical processes are more environmentally friendly. However, the chalcopyrite leaching process has not been widely adopted due to its low recovery rate and slow leaching rate. Therefore, research on the chalcopyrite leaching mechanism and improving the chalcopyrite leaching rate have always been the focus of hydrometallurgy.

Many researchers have observed a passive layer during chalcopyrite leaching. However, there is still disagreement about the composition of the passive layer. The reported possible passivating species mainly consist of polysulfide $\left(\mathrm{S}_{\mathrm{n}}{ }^{2-}\right)$ elemental sulfur $\left(\mathrm{S}^{0}\right)$ and insoluble sulfate $\left(\mathrm{SO}_{4}{ }^{2-}\right)$. Linge [2] found that more iron than copper dissolved from the lattice during the initial stage of chalcopyrite leaching, producing metal-deficient polysulfide of the chalcopyrite surface. Yang [3] analyzed the leaching process of chalcopyrite by XANES, and found that the polysulfides generated on the surface of chalcopyrite in the initial stage were $\mathrm{CuS}_{\mathrm{n}}$-like species. With further $\mathrm{Cu}$ leaching, $\mathrm{CuS}_{\mathrm{n}}$-like species were transformed into $S_{n}$-like species. The slow oxidation rate of $S_{n}$-like species was the reason for the passivation. Dutrizac [4] found that the chalcopyrite surface produced approximately 
$94 \%$ elemental sulfur and $6 \%$ sulfate in the sulfuric acid solution at $95{ }^{\circ} \mathrm{C}$, and believed that elemental sulfur was the main passivating species of chalcopyrite in the ferric sulphate system. Klauber [5] believed that the reactivity of polysulfide was strong, and it could be oxidized to elemental sulfur by oxygen; the elemental sulfur could cause the passivation of chalcopyrite, but it was easy to peel off from chalcopyrite surface, and jarosite should be the main passivating species.

The passive layer can be dissolved at high redox potential, except jarosite. The effects of oxidants on chalcopyrite leaching have extensively been studied; for example, dichromate [6], permanganate [7], $\mathrm{MnO}_{2}$ [8], chlorate [9], nitrate [10], hydrogen peroxide [11], etc. The results showed that the oxidants could observably promote the dissolution of chalcopyrite, even under mild conditions. Antonijevic [12] reported that the chalcopyrite leaching conformed to the shrinking core model with the presence of hydrogen peroxide. The chemical reaction was the controlling step and increasing the concentration of hydrogen peroxide could significantly accelerate the chalcopyrite dissolution rate. Toro [13] found that chalcopyrite can dissolve rapidly at room temperature when working at 4:1 ratio of oxidizing agent $\left(\mathrm{MnO}_{2}\right)$ : chalcopyrite in chlorinated acid medium.

The rest potential of pyrite is higher than chalcopyrite, therefore pyrite is more stable than chalcopyrite [14]. Galvanox ${ }^{\mathrm{TM}}$ process increases the reduction site of $\mathrm{Fe}^{3+}$ to $\mathrm{Fe}^{2+}$ by adding insoluble pyrite, and alleviates the negative impact of passive layer on chalcopyrite dissolution [15]. An appropriate amount of $\mathrm{Ag}^{+}$can improve the electrical conductivity of the sulfur layer on the surface of chalcopyrite, and further strengthen the galvanic effect between pyrite and chalcopyrite [16]. In addition, Zhao [17] believed that $\mathrm{Fe}^{2+}$ generated by the pyrite oxidation could reduce the redox potential to the range of promoting the chalcopyrite dissolution. A technique developed by Dixon [18] showed that the recovery of copper can reach $98 \%$ or more in just $4 \mathrm{~h}$ retention time when the ratio of pyrite:chalcopyrite is 2:1, the solution redox potential is controlled at $470 \mathrm{mV}$ (vs. $\mathrm{Ag} / \mathrm{AgCl}$, the same below), and the atmosphere temperature is $80^{\circ} \mathrm{C}$.

The elements $\mathrm{Cu}, \mathrm{Fe}$ and $\mathrm{S}$ in chalcopyrite have multiple valence states, which is the reason for the diversity of intermediate products. The redox potential determines the oxidation degree of chalcopyrite, which in turn determines the type of intermediate products [19]. Chalcopyrite dissolution consists of two stages, the chemical reaction control stage with a trace of surface products, and the diffusion control stage with a mass of surface products. Iron ions can promote the rate of chemical reaction stage, thus accelerating the transformation from chemical reaction control to diffusion control [20]. Chalcopyrite leaching and electrochemical studies show that at a low redox potential of $400-420 \mathrm{mV}$, chalcopyrite is actively dissolved, and less affected by the surface product layer. Chalcopyrite is reduced by $\mathrm{Fe}^{2+}$ and $\mathrm{Cu}^{2+}$ to $\mathrm{Cu}_{2} \mathrm{~S}$ at low redox potential [21]. In ferric sulfate solution, $\mathrm{Cu}_{2} \mathrm{~S}$ is more readily dissolved than chalcopyrite. Ahmadi [22] studied the electrochemical bioleaching of chalcopyrite and indicated that the copper leaching rate under the redox potential controlled at $400-425 \mathrm{mV}$ was $35 \%$ higher than that under the natural redox potential. Kametani [23] found that the chalcopyrite leaching was promoted when the redox potential of the solution was $400-430 \mathrm{mV}$. However, when the potential was higher than $450 \mathrm{mV}$, chalcopyrite leaching was significantly inhibited. Because pyrite began to be oxidized to sulfate, the jarosite layer played a passivation role on the surface of chalcopyrite [7].

In conclusion, different redox potentials and the types of intermediate products significantly affect the process of chalcopyrite leaching. The purpose of this study was to develop a redox potential controlling device using microcontroller technology and evaluate the effect of redox potential on the leaching of chalcopyrite. The leaching mechanism of chalcopyrite was deduced by XRD, XPS, and SEM-EDS detection of the leaching residue. The device used in this study controlled the redox potential of the solution through feedback control, which can reduce the unnecessary use of an oxidizer, so it can provide a reference for the development of the new process of chalcopyrite leaching. 


\section{Materials and Methods}

\subsection{Minerals}

All chalcopyrite used in this study was from Hunan Province, China. X-ray diffraction (XRD) analysis (Figure 1) showed that the chalcopyrite was of high purity with only a small amount of quartz and pyrite. The chemical composition of the ore sample, as shown in Table 1, indicated that the chalcopyrite contained $33.85 \% \mathrm{Cu}, 29.75 \% \mathrm{Fe}$ and $51.58 \%$ $\mathrm{S}$. The presence of pyrite and Ag is conducive to chalcopyrite oxidation leaching due to the galvanic effect between pyrite and chalcopyrite and the activation effect of Ag by improving the electrical conductivity of the sulfur layer on the chalcopyrite surface. The mineral particles were ground to particles of $-74 \mu \mathrm{m}$ using a ceramic ball mill (Changsha Tencan powder technology Co. Ltd., Changsha, China).

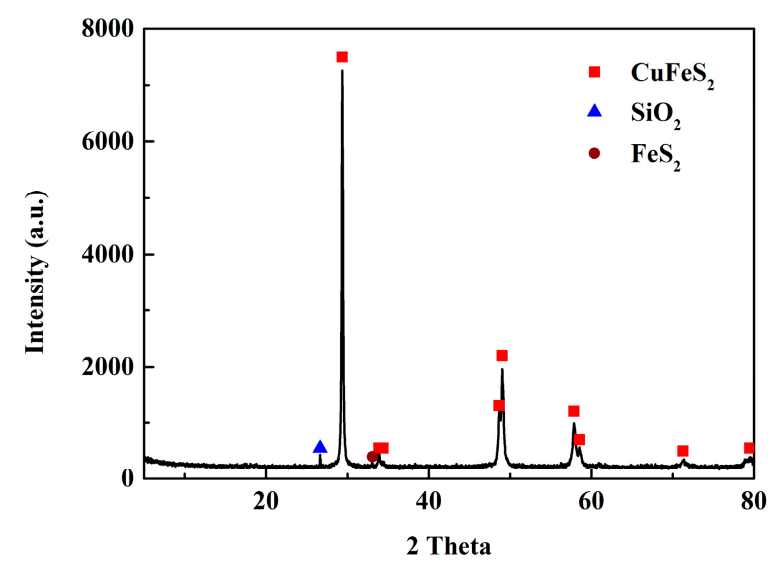

Figure 1. X-ray diffractogram pattern of the ore of chalcopyrite.

Table 1. Chemical composition of the ore.

\begin{tabular}{cccccccccc}
\hline Element. & $\mathbf{O}$ & $\mathbf{A l}$ & $\mathbf{S i}$ & $\mathbf{S}$ & $\mathbf{K}$ & $\mathbf{C a}$ & $\mathbf{F e}$ & $\mathbf{C u}$ & $\mathbf{A g}$ \\
\hline Wt. $\%$ & 0.14 & 0.025 & 0.098 & 34.16 & 0.009 & 0.01 & 29.75 & 33.85 & 0.022 \\
\hline
\end{tabular}

\subsection{Apparatus}

The reaction apparatus used in this experiment, as shown in Figure 2, consisted of a $500 \mathrm{~mL}$ four-hole boiling flask, a stirrer, a water bath, and a redox potential controlling device.

The microcontroller system was used to collect the real-time redox potential data of the solution and controlled the release of redox potential regulators by the peristaltic pump. The detailed working process is as follows: collecting the voltage data of the redox potential composite electrode (vs. $\mathrm{Ag} / \mathrm{AgCl}$ ) through a microcontroller, and then sending a control signal to the peristaltic pump after comparing with the set threshold value. If the redox potential of the solution was higher than the threshold value, the reducing agent was added; otherwise, the oxidizing agent was added. Real-time volume of the redox potential regulator was obtained by using graduated container. The computer was only used to easily read real-time redox potential data.

The division value of the redox potential control device was $0.6 \mathrm{mV}$. The model of microcontroller was STC15F2K60S2 and used an ADS1015 analog to digital converter (ADC). 


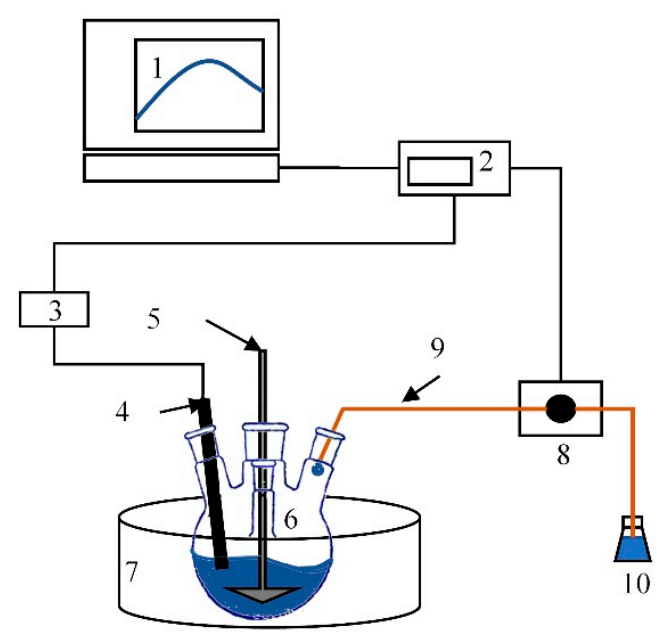

Figure 2. Schematic diagram of the redox potential controlling device: (1) host computer, (2) microcontroller, (3) analog to digital converter (ADC), (4) redox potential composite electrode, (5) stirrer, (6) four-hole boiling flask, (7) water bath heater, (8) peristaltic pump, (9) rubber tube, (10) redox potential regulator.

\subsection{Procedures}

Solutions with different redox potentials were prepared by adding redox regulators to sulfuric acid solutions with a $\mathrm{pH}$ of 0.7 and a total Fe concentration of $0.1 \mathrm{~mol} / \mathrm{kg}$. The redox potential regulators were $\mathrm{H}_{2} \mathrm{O}_{2}(3 \mathrm{wt} . \%)$ as the oxidant and ascorbic acid (8 wt.\%) as the reductant.

All leaching tests were carried out at a stirring speed of $300 \mathrm{rpm}$, a pulp concentration of $2 \%$ (200 mL leaching solution and $4 \mathrm{~g}$ ore), and a temperature of $60{ }^{\circ} \mathrm{C}$. During the test, the redox potential of the solution was controlled by the redox potential controlling device, and data were recorded every $10 \mathrm{~s}$.

The initial $\mathrm{pH}$ of the leaching solution was measured using a glass electrode. During the leaching test, the solution was regularly sampled, $50 \mu \mathrm{L}$ each time, to measure the concentration of $\mathrm{Cu}^{2+}$ and Fe by inductively coupled plasma atomic emission spectrometry (ICP-AES, Agilent 720ES). The sampling loss was compensated by adding equal volumes of acid. After filtration, washing and vacuum drying, the residue underwent XRD, SEM-EDS, and XPS.

\subsection{Surface Analysis}

The S speciation transformations on the chalcopyrite surfaces were analyzed by X-ray photoelectron spectroscopy (XPS), which was carried out using the EscaLab Xi+ model, and the spectra were recorded with a constant pass energy of $20 \mathrm{eV}$ and $0.1 \mathrm{eV} /$ step using an $\mathrm{Al} \mathrm{K} \propto$ X-ray source. The obtained XPS spectra were fitted by using Thermo Avantage 5.52 software. During the fitting process, the binding energies of the spectra were calibrated by the $C$ 1s level at $284.8 \mathrm{eV}$, the background was achieved by using the Shirley method, and the spectrum was fitted by the Gauss-Lorentz line (SGL) function.

The phase compositions of chalcopyrite were analyzed by X-ray diffraction (XRD, Advance D8/Bruker). Jade6 software was used to analyze the XRD patterns. The microstructure of the pyrite was studied in a scanning electron microscope (SEM, JSM-6490LV/JEOL) equipped with an energy dispersive spectrometer (EDS, Nepture XM 4/EDAX).

\section{Experimental Results}

\subsection{Leaching under Different Initial Redox Potentials}

This study first investigated the leaching of chalcopyrite under initial redox potentials of $600 \mathrm{mV}$ and $400 \mathrm{mV}$. Only the initial redox potentials were set to different values, and the redox potentials were not fixed in the test process. Figure $3 b$ shows the change in 
redox potential with time during the experiment. As shown in Figure 3a, the $\mathrm{Cu}$ leaching rate of the experimental group with an initial redox potential of $400 \mathrm{mV}$ at $23.5 \mathrm{~h}$ was 3.47 -fold greater than that of the experimental group with initial redox potential of $600 \mathrm{mV}$. Therefore, a lower redox potential is more conducive to the leaching of chalcopyrite.
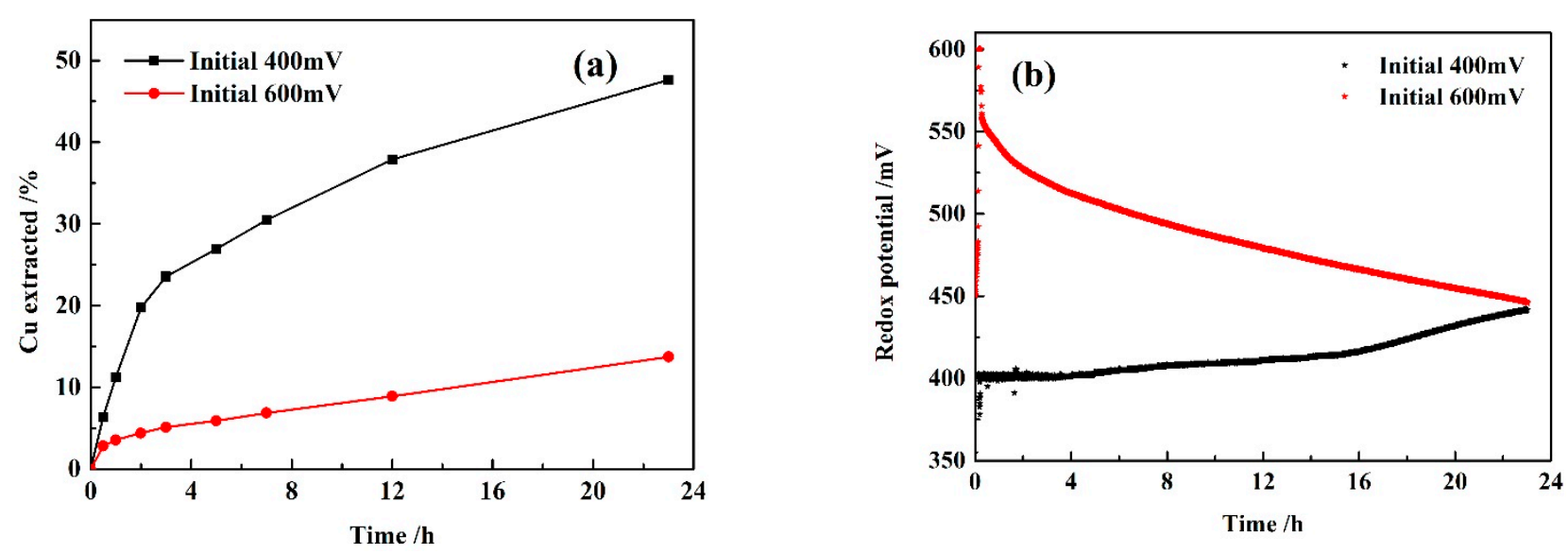

Figure 3. $\mathrm{Cu}$ leaching rate (a) and real-time redox potential data of the leaching solution (b), with initial redox potentials of $400 \mathrm{mV}$ and $600 \mathrm{mV}$, respectively; the redox potential was not fixed in the test process.

In the experimental group with an initial redox potential of $600 \mathrm{mV}$, the redox potential of the solution dropped sharply within the first few minutes after adding the chalcopyrite, and then decreased slowly to $455 \mathrm{mV}$ at $23.5 \mathrm{~h}$, as shown in Figure 3b. The reason for the decrease in redox potential was that $\mathrm{Fe}^{3+}$ was consumed as chalcopyrite was being oxidized. The reasons for the sharp drop of redox potential in the initial stage were the rapid reaction of the fine particles and the surface reconstruction of the ore. In the experimental group with an initial redox potential of $400 \mathrm{mV}$, the potential of the solution began to rise slowly around $5 \mathrm{~h}$, and began to rise rapidly after $16 \mathrm{~h}$, reaching $449 \mathrm{mV}$ at $23.2 \mathrm{~h}$. At the initial stage, the minerals were oxidized, but at the later stage, $\mathrm{Fe}^{2+}$ was oxidized and the minerals or intermediate products were reduced. The same experimental phenomenon was observed by Cordoba [24] and Third [25]. Therefore, the leaching mechanism of chalcopyrite is different under different redox potentials.

\subsection{Controlled Redox Potential Leaching}

The redox potential controlling device, shown in Figure 2, was used to perform the leaching test of chalcopyrite at the redox potentials of $350 \mathrm{mV}, 400 \mathrm{mV}, 450 \mathrm{mV}, 500 \mathrm{mV}$, and $600 \mathrm{mV}$. As shown in Figure 4, the redox potential was precisely controlled. When the target redox potential was $450 \mathrm{mV}, 500 \mathrm{mV}$, and $600 \mathrm{mV}$, the ore sample was oxidized, resulting in a decreasing trend of the redox potential. Oxidizer was added to maintain the redox potential to the target value.

When the target redox potential was $400 \mathrm{mV}$ and $350 \mathrm{mV}$, the redox potential showed a decreasing trend in the first five hours, and oxidant was added; however, after about $5 \mathrm{~h}$, the redox potential showed an increased trend, and reductant was added. 


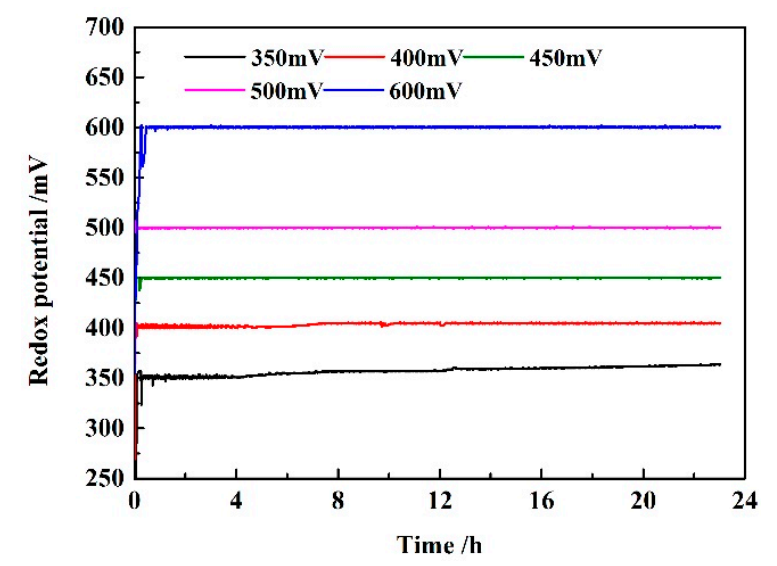

Figure 4. Real-time redox potential data with the redox potential controlling device.

Figure 5 shows the test results of the redox potential fixed at $350 \mathrm{mV}, 400 \mathrm{mV}, 450 \mathrm{mV}$, $500 \mathrm{mV}$ and $600 \mathrm{mV}$. At the redox potential of $400 \mathrm{mV}$, the leaching rates of $\mathrm{Cu}$ and Fe were the same (Figure $5 \mathrm{~b}$ ). However, at the lower potential of $350 \mathrm{mV}$ and the higher potentials of $450 \mathrm{mV}, 500 \mathrm{mV}$ and $600 \mathrm{mV}$, the leaching rate of Fe was higher than $\mathrm{Cu}$. In all the leaching tests, chalcopyrite was leaching at a faster rate at the beginning and then gradually slowed down. At the redox potential of $400 \mathrm{mV}$, chalcopyrite was leached at a faster rate before $7 \mathrm{~h}$; however, after $7 \mathrm{~h}$, the inhibition was more obvious, and the leaching almost stopped. The $\mathrm{Cu}$ leaching rate reached $32 \%$ at $7 \mathrm{~h}$, and only $15 \%$ in the other experimental groups. However, at $23.5 \mathrm{~h}$, the $\mathrm{Cu}$ leaching rate was only $37 \%$.

Figure $5 \mathrm{f}$ shows that the leaching of $\mathrm{Cu}$ was faster when the redox potential was maintained at $400 \mathrm{mV}$, which was identical with previous experimental results [24,26-28]. When the redox potential was between $400 \mathrm{mV}$ and $500 \mathrm{mV}$, the leaching of $\mathrm{Cu}$ decreased. When the redox potential was over $500 \mathrm{mV}, \mathrm{Cu}$ leaching increased again. This experimental result is consistent with the activation, passivation, and over-passivation phenomenon in the presence of a passivating substance. The activation potential is $400 \mathrm{mV}$, the passivation potential ranges from 400 to $500 \mathrm{mV}$, and the over-passivation potential is above $500 \mathrm{mV}$.
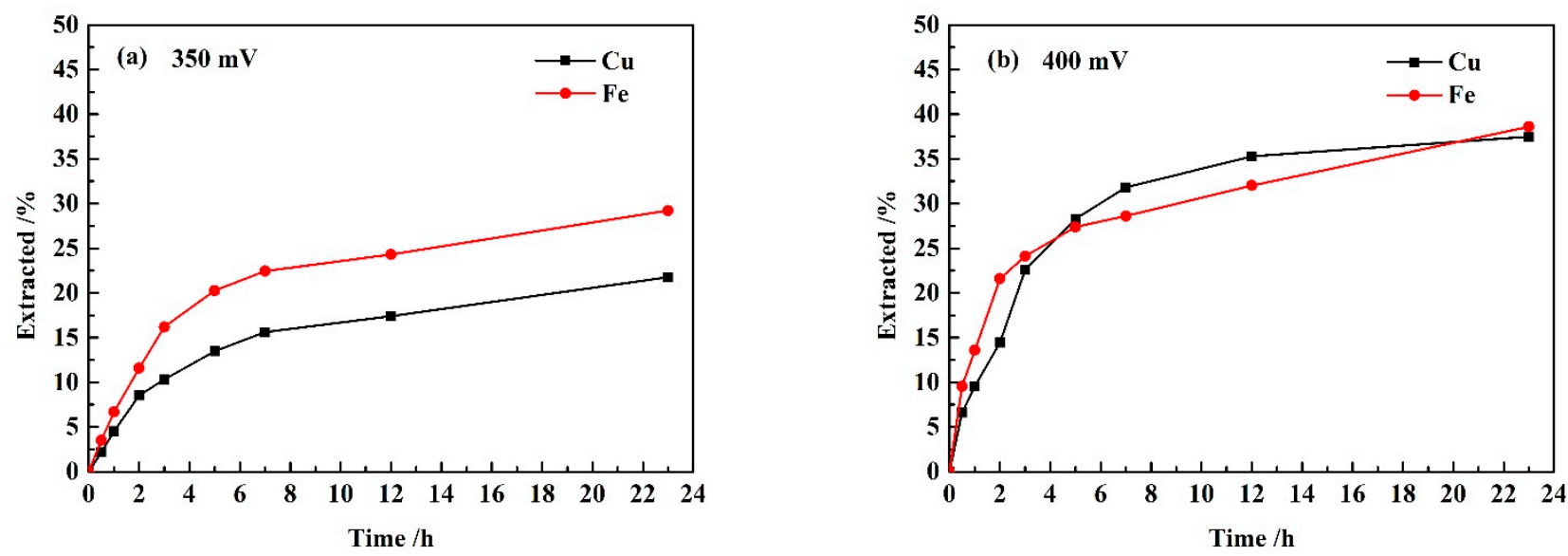

Figure 5. Cont. 

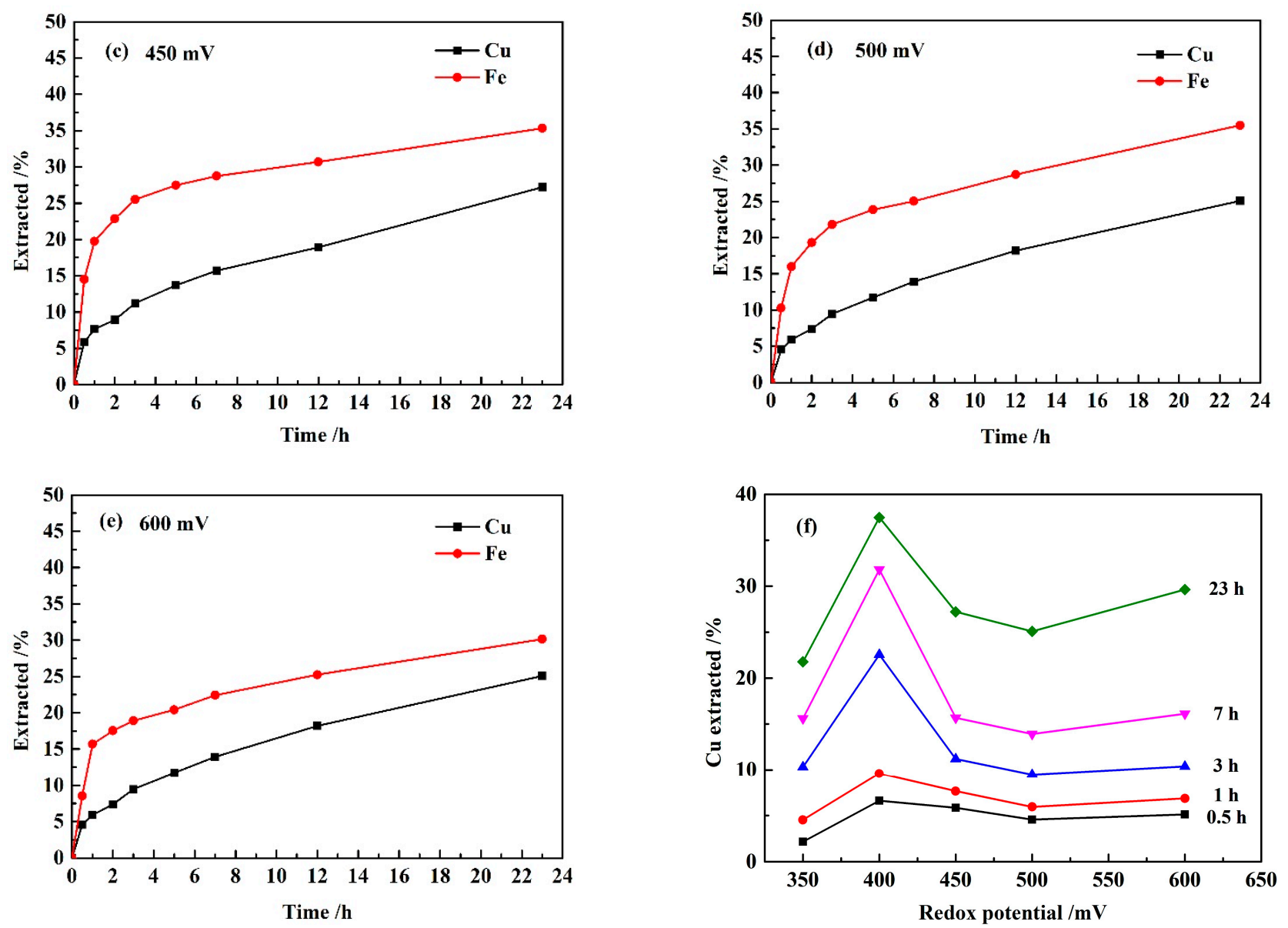

Figure 5. In the controlled redox potential test process, the redox potentials (a-e) were fixed at $350 \mathrm{mV}, 400 \mathrm{mV}, 450 \mathrm{mV}$, $500 \mathrm{mV}$ and $600 \mathrm{mV}$, respectively, showing the $\mathrm{Cu}$ and Fe leaching rates at different times; (f) Cu leaching rate at different redox potentials.

\subsection{Analysis of Chalcopyrite Leaching Residue}

According to the above leaching test results, chalcopyrite undergoes oxidation reaction at high redox potential, but at low redox potential, there was a reduction reaction causing the increase in redox potential. Therefore, the leaching mechanism of chalcopyrite is different at various redox potentials. Different intermediate products may be produced, such as polysulfide, elemental sulfur, and jarosite. To further study the leaching mechanism of chalcopyrite at various redox potential, the leaching residues with redox potentials fixed at $400 \mathrm{mV}$ and $600 \mathrm{mV}$ were analyzed.

\subsubsection{XPS Analysis}

The $\mathrm{S}$ speciation transformations on the chalcopyrite surfaces were analyzed by $\mathrm{X}$ ray photoelectron spectroscopy (XPS), as shown in Table 2. Due to spin-orbit splitting, $S 2 p$ peak presents a $S 2 p_{3 / 2}$ and $S 2 p_{1 / 2}$ doublet. The $S 2 p$ spectra were fitted on the Thermo Scientific ${ }^{\mathrm{TM}}$ Avantage software. The area ratio of the two peaks fitted was 2:1, and the energy difference of the two peaks was $1.2 \mathrm{eV}$. Figures $6 \mathrm{~d}$ and $7 \mathrm{c}$ show the fitting results of $S 2 p$ peaks. The $S 2 p_{2 / 3}$ peaks were found to be $161.36 \mathrm{eV}$ (full width at half maximum, FWHM = 0.84), $162.41 \mathrm{eV}(\mathrm{FWHM}=0.84), 163.41 \mathrm{eV}(\mathrm{FWHM}=0.84), 164.2 \mathrm{eV}$ $(\mathrm{FWHM}=0.84)$, and $168.9 \mathrm{eV}(\mathrm{FWHM}=1.48)$, respectively. These peaks are attributed to monosulfide $\left(\mathrm{S}^{2-}\right)$, disulfide $\left(\mathrm{S}_{2}{ }^{2-}\right)$, polysulfide $\left(\mathrm{S}_{\mathrm{n}}{ }^{2-}\right)$, elemental sulfur $\left(\mathrm{S}^{0}\right)$, and sulfate $\left(\mathrm{SO}_{4}{ }^{2-}\right)$ [29]. According to the fitting results in Figures $6 \mathrm{~d}$ and $7 \mathrm{c}$ and the $\mathrm{S}$ species on the ore sample surface as shown in Table $2, \mathrm{~S}^{2-}, \mathrm{S}_{2}{ }^{2-}, \mathrm{S}_{\mathrm{n}}{ }^{2-}, \mathrm{S}^{0}$, and $\mathrm{SO}_{4}{ }^{2-}$ were the major species of $S$ on the leaching residue surface. According to the $S$ distribution on the surface of 
the ore sample, the oxidation of chalcopyrite was complex with multiple steps. According to the number of electrons obtained, the oxidation of $\mathrm{S}^{2-}$ proceeds in the following process:

$$
\mathrm{S}^{2-} \rightarrow \mathrm{S}_{2}^{2-} \rightarrow \mathrm{S}_{\mathrm{n}}^{2-} \rightarrow \mathrm{S}^{0} \rightarrow \mathrm{SO}_{4}^{2-}
$$

Whether it was a low or a high redox potential, the leaching residue contained $\mathrm{S}^{2-}$, $\mathrm{S}_{2}{ }^{2-}, \mathrm{S}_{\mathrm{n}}{ }^{2-}$ and $\mathrm{S}^{0}$ after $23.5 \mathrm{~h}$ of leaching. Due to the presence of jarosite deposition at high redox potential, $10.84 \%$ of the sulfur existed in the sulfate. However, sulfate was not detected in the low redox potential group.

Table 2. XPS test results of the leaching residue.

\begin{tabular}{cccccc}
\hline \multirow{2}{*}{ Experimental Group } & \multicolumn{5}{c}{ Percentage (\%) } \\
\cline { 2 - 6 } & $\mathbf{S}^{\mathbf{2 -}}$ & $\mathbf{S}_{2}{ }^{2-}$ & $\mathbf{S}_{\mathbf{n}}{ }^{\mathbf{}}$ & $\mathbf{S}^{\mathbf{0}}$ & $\mathbf{S O}_{4}{ }^{{ }^{-}-}$ \\
\hline $400 \mathrm{mV}$ & 62.24 & 15.68 & 13.76 & 8.32 & 0 \\
$600 \mathrm{mV}$ & 56.10 & 13.19 & 12.23 & 7.65 & 10.84 \\
\hline
\end{tabular}
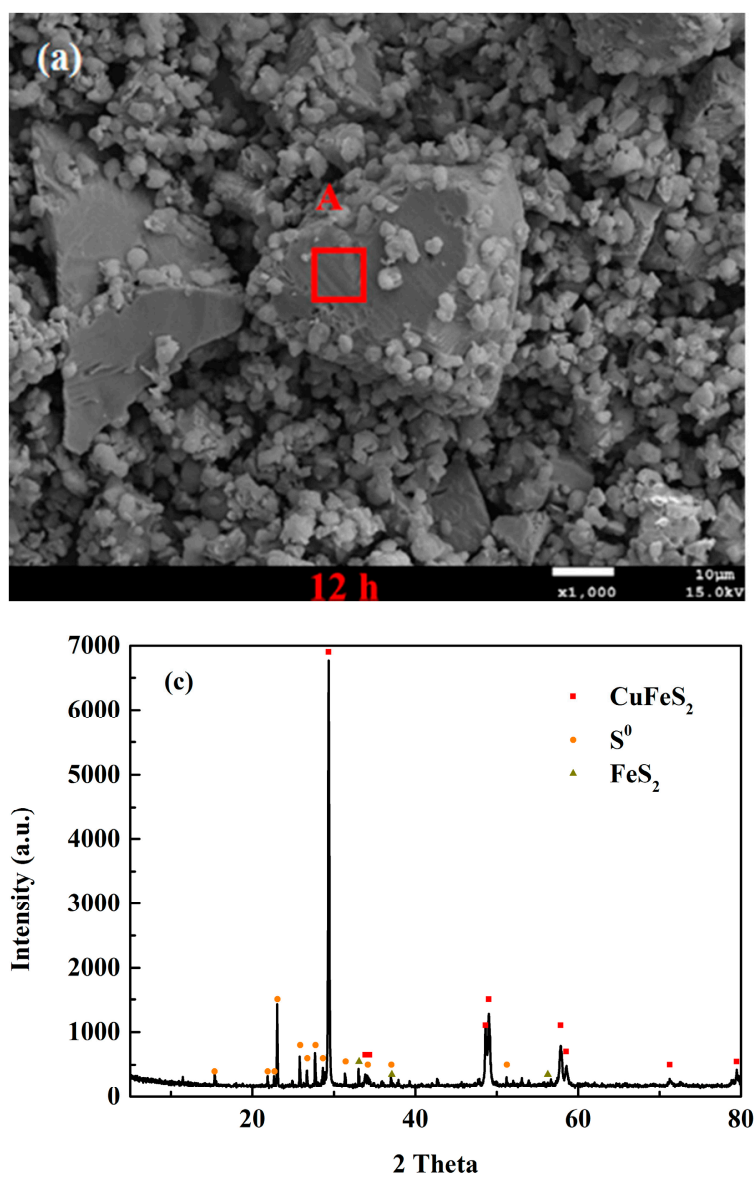
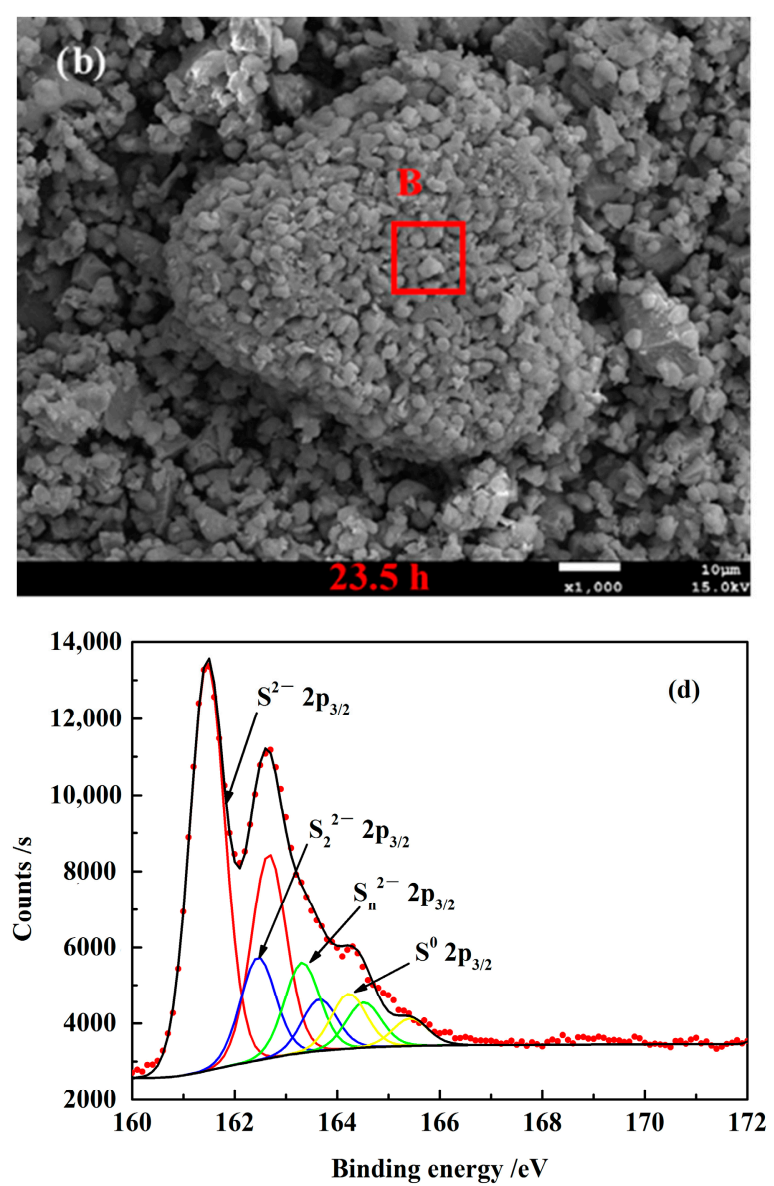

Figure 6. In the experimental group with redox potential of $400 \mathrm{mV}$, solid-phase SEM image at $12 \mathrm{~h}$ of chalcopyrite leaching (a), and solid-phase SEM image (b), XRD image (c), and XPS image (d) at $23.5 \mathrm{~h}$ of chalcopyrite leaching. (A and B in the figures are EDS detection areas). 

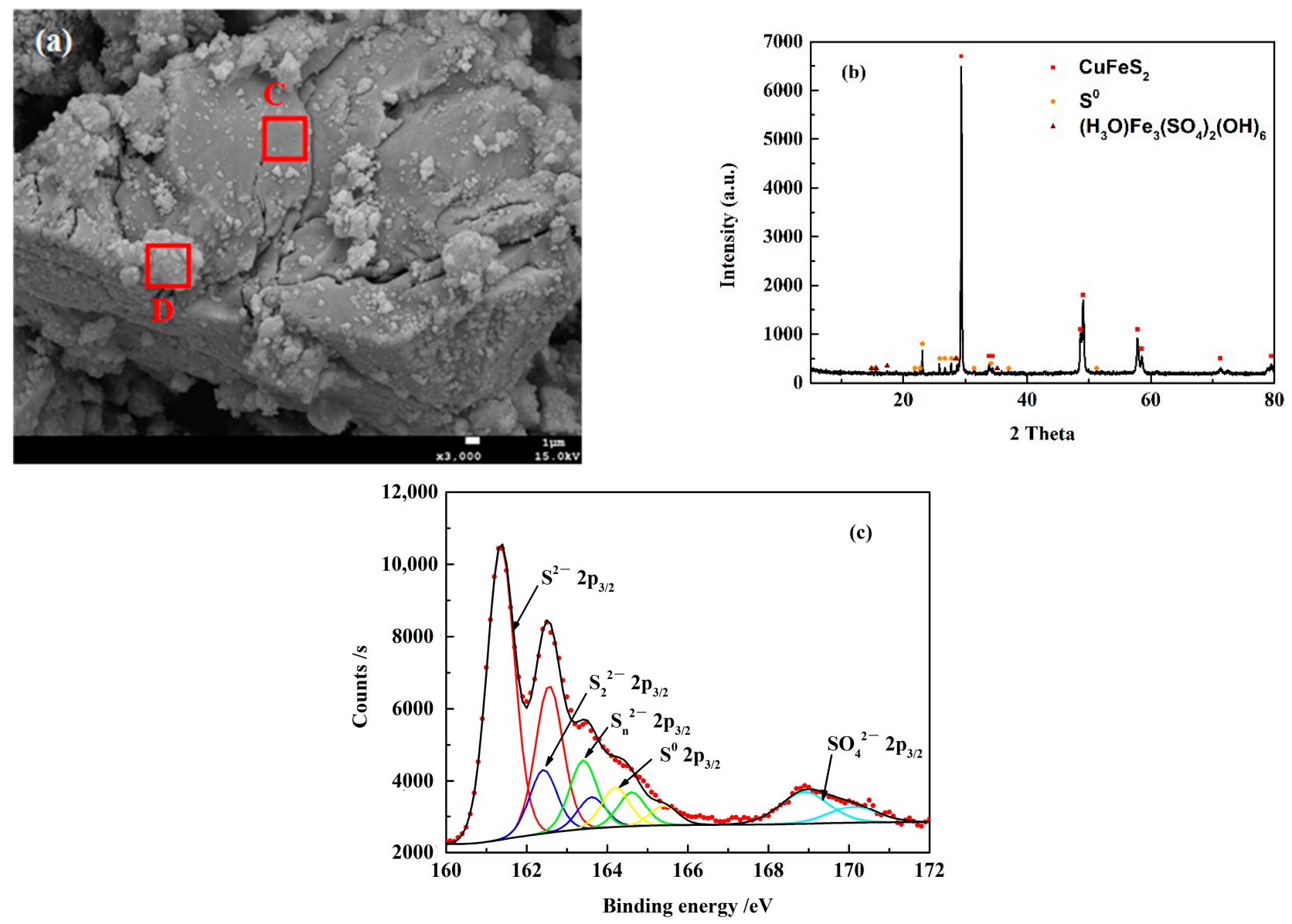

Figure 7. For the experimental group with a redox potential of $600 \mathrm{mV}$, solid phase SEM image (a), XRD image (b), and XPS image (c) at $23.5 \mathrm{~h}$ of chalcopyrite leaching. ( $\mathrm{C}$ and $\mathrm{D}$ in the figure are EDS detection areas).

\subsubsection{XRD and SEM-EDS Analysis}

In the experimental group with redox potential fixed at $400 \mathrm{mV}, \mathrm{Cu}$ leaching rate was significantly different in the initial and later stages. Therefore, leaching residue at $12 \mathrm{~h}$ and $23.5 \mathrm{~h}$ were selected for SEM detection as shown in Figure $6 \mathrm{a}, \mathrm{b}$, and area A of the chalcopyrite surface and area B of the particles on the ore surface were selected for EDS detection.

According to the SEM results, many granular intermediate products were generated and attached to the chalcopyrite surface, and the intermediate products increased over time. At $23.5 \mathrm{~h}$, mineral particles were almost completely covered by particles formed by intermediate products (Figure 6b), and the chalcopyrite leaching was inhibited at this time, as shown in Figure $5 b$. Therefore, after leaching for a period of time, the covering of a large number of intermediate products had a significant negative effect on chalcopyrite leaching.

The EDS detection depth is 1-2 $\mu \mathrm{m}$, and the particle size formed by the intermediate was $2 \mu \mathrm{m}$ on average; thus, EDS detection could be used as the basis to judge the elements contained in the intermediate products. The results (Table 3 ) show that the particles formed by the intermediate products not only contain a large amount of $\mathrm{S}$, but also $\mathrm{Cu}$ and $\mathrm{Fe}$. The area A that is not covered by the intermediate is still the intrinsic chalcopyrite.

The XRD result shows that the newly formed phase was elemental sulfur. In addition, pyrite was nonreactive at low redox potential. With the leaching of chalcopyrite, the characteristic peak of pyrite in the ore sample, as shown in Figure 6c, becomes more apparent. 
Table 3. EDS results of the leaching residue.

\begin{tabular}{cccc}
\hline \multirow{2}{*}{ Detecting Area } & \multicolumn{3}{c}{ Percentage \% } \\
\cline { 2 - 4 } & Cu & Fe & S \\
\hline $400 \mathrm{mV}-\mathrm{A}$ & 26.51 & 25.33 & 48.16 \\
$400 \mathrm{mV}-\mathrm{B}$ & 20.18 & 16.45 & 63.37 \\
$600 \mathrm{mV}-\mathrm{C}$ & 27.02 & 26.69 & 46.29 \\
$600 \mathrm{mV}-\mathrm{D}$ & 18.46 & 21.66 & 59.88 \\
\hline
\end{tabular}

The surface morphology of chalcopyrite at a redox potential of $600 \mathrm{mV}$ (Figure 7a) was significantly different from that at a redox potential of $400 \mathrm{mV}$ (Figure 6a,b). At high redox potential, intermediate products such as polysulfide and elemental sulfur were oxidized to sulfate, so the particles formed by the intermediate products on the ore surface were significantly reduced. However, crystals with particle size less than $1 \mu \mathrm{m}$ were formed in large quantities, which not only existed in intermediate particles, but also densely distributed on the mineral surface.

The XRD result (Figure $7 \mathrm{~b}$ ) shows that the newly produced phases included sulfur elemental and hydroniumjarosite $\left(\mathrm{H}_{3} \mathrm{OFe}_{3}\left(\mathrm{SO}_{4}\right)_{2}(\mathrm{OH})_{6}\right)$ at the redox potential of $600 \mathrm{mV}$. EDS results show that the Fe content in area D was higher than that in area $\mathrm{B}$, and the sulfate detected by XPS indicates that the newly formed crystal could be hydroniumjarosite detected by XRD. Although a large amount of hydroniumjarosite was attached to the mineral particles, there was still a partially uncovered surface, such as area C.

\section{Mechanism of Chalcopyrite Leaching}

At $600 \mathrm{mV}$, the microstructure of the leaching residues showed that most of the surface of chalcopyrite particles was still uncovered by elemental sulfur and jarosite. Therefore, elemental sulfur and jarosite may not be the main cause of chalcopyrite passivation.

When the redox potential of the solution was higher than $450 \mathrm{mV}$, the Fe element dissolved prior to $\mathrm{Cu}$ at the beginning of dissolution process, and then the presence of polysulfide $\left(\mathrm{S}_{2}{ }^{2-}\right.$ and $\left.\mathrm{S}_{\mathrm{n}}{ }^{2-}\right)$ on the surface of chalcopyrite. Therefore, the chalcopyrite passivation may be caused by the formation of metal-deficient polysulfides on the chalcopyrite surface due to the preferential leaching of Fe. Linge [2] obtained the same conclusion when studying the electrochemical dissolution mechanism of chalcopyrite by a potentiometric titration technique. The thickness of a metal-deficient polysulfide passivation film on the chalcopyrite surface is less than $1 \mu \mathrm{m}$ [30]. Therefore, it was difficult to identify metal-deficient polysulfides on the chalcopyrite surface by SEM. However, when the redox potential reached $600 \mathrm{mV}$, the dissolution of chalcopyrite was accelerated. The possible reason is that some of the polysulfides on the mineral surface were oxidized and dissolved under high potential; thus, the passivation was weakened.

At $400 \mathrm{mV}$, elements Fe and Cu were leached simultaneously. Passivation of polysulfides appeared to have been overcome; however, XPS results showed that polysulfide films still existed.

The Pourbaix diagram of chalcopyrite drawn by HSC Chemistry 6 software, as shown in Figure 8. There was a deviation between ion activity and concentration in the actual solution; therefore, Figure 8 is only for qualitative analysis. The upper boundary of chalcopyrite stability region is connected with $\mathrm{CuS}$ and $\mathrm{FeS}_{2}$. At a redox potential of $400 \mathrm{mV}$, Cordoba [23] found a presence of $\mathrm{CuS}$ in the chalcopyrite leaching process. Therefore, at low $\mathrm{pH}, 400 \mathrm{mV}$ may be the stable redox potential for the polysulfide and elemental sulfur produced by the oxidation of chalcopyrite. In this study, the XRD result of the leaching residue showed that the pyrite was not oxidized and stable at $400 \mathrm{mV}$. Therefore, $400 \mathrm{mV}$ could also be the stable potential for pyrite. Kametani [23] reported that pyrite began to oxidize at $450 \mathrm{mV}$ (vs. SCE, saturated calomel electrode). 


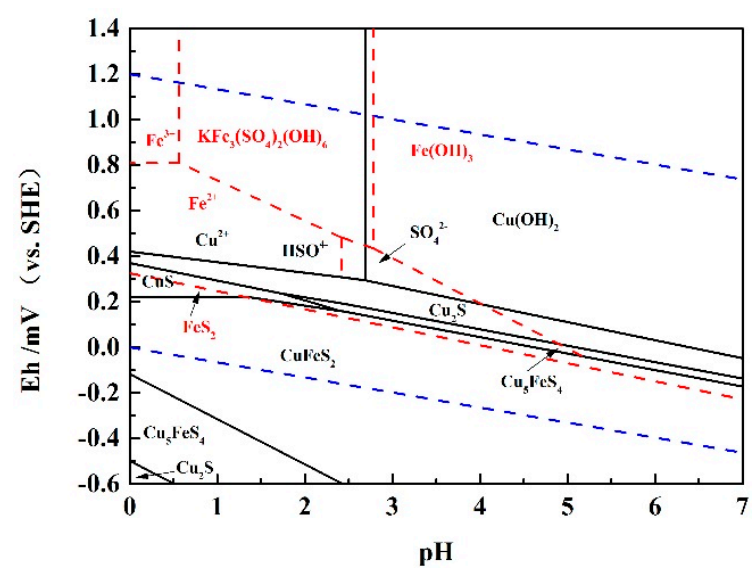

Figure 8. Pourbaix diagram of chalcopyrite (black solid line) and pyrite (red dashed line). (SHE stands for standard hydrogen electrode).

At a potential of $400 \mathrm{mV}$, the galvanic effect between pyrite and chalcopyrite may be the reason for the rapid dissolution of chalcopyrite over the passivation of polysulfide. The success of Galvanox ${ }^{\mathrm{TM}}$ processes also demonstrates the important role of pyrite in overcoming the surface passivation of chalcopyrite [18]. At high potential, pyrite was oxidized to destroy the galvanic effect, so the copper leaching rate decreased significantly. At $400 \mathrm{mV}$, the dissolution of chalcopyrite could not be hindered until the granular intermediates including elemental sulfur and polysulfides accumulated to a certain amount on the chalcopyrite surface, as shown in Figure $7 \mathrm{~b}$.

The dissolution of chalcopyrite produces elemental sulfur, and $400 \mathrm{mV}$ is the stable redox potential of $\mathrm{CuS}$ and $\mathrm{FeS}_{2}$. Therefore, it is speculated that when chalcopyrite was leaching at $400 \mathrm{mV}$, the reason for the increasing tendency of redox potential in the later period may be caused by the formation of $\mathrm{CuS}$ and $\mathrm{FeS}_{2}$ by $\mathrm{Fe}^{2+}, \mathrm{Cu}^{2+}$ and elemental sulfur:

$$
\begin{gathered}
2 \mathrm{~S}^{0}+3 \mathrm{Fe}^{2+}=\mathrm{FeS}_{2}+2 \mathrm{Fe}^{3+} \\
\mathrm{S}^{0}+\mathrm{Cu}^{2+}+2 \mathrm{Fe}^{2+}=\mathrm{CuS}+2 \mathrm{Fe}^{3+}
\end{gathered}
$$

When the redox potential was fixed at $350 \mathrm{mV}$, almost all Fe in the solution existed as $\mathrm{Fe}^{2+}$. Even though pyrite was stable, chalcopyrite was leached slowly under the action of ferrous and sulfuric acid because of the weak oxidation capacity of the solution. Hiroyoshi [31] believed that $\mathrm{Fe}^{2+}$ would inhibit the chalcopyrite leaching, but in the presence of a large amount of $\mathrm{Cu}^{2+}, \mathrm{Fe}^{2+}$ could reduce chalcopyrite to $\mathrm{Cu}_{2} \mathrm{~S}$ :

$$
\mathrm{CuFeS}_{2}+3 \mathrm{Cu}^{2+}+3 \mathrm{Fe}^{2+}=2 \mathrm{Cu}_{2} \mathrm{~S}+4 \mathrm{Fe}^{3+}
$$

This reaction also revealed the reason why the solution redox potential had an upward trend in the later stage, when the redox potential was fixed at $350 \mathrm{mV}$.

\section{Conclusions}

In this paper, chalcopyrite leaching tests were carried out with a redox potential controlling device based on microcontroller technology. The effect of redox potential on chalcopyrite leaching at $60^{\circ} \mathrm{C}$ was studied. The preferential dissolution of Fe led to the formation of Fe-deficient polysulfides on the surface of chalcopyrite, which hindered the diffusion of ions from the chalcopyrite/passivation film interface to passivation film/solution interface, thus resulting in passivation. At $400 \mathrm{mV}$, due to the presence of pyrite contained in the raw ore or produced by chalcopyrite oxidation, the galvanic effect between chalcopyrite and pyrite overcame the passivation of chalcopyrite by metal-deficient polysulfides. When the redox potential of the solution was increased, the pyrite was oxidized and the galvanic effect between chalcopyrite and pyrite was destroyed, so the $\mathrm{Cu}$ leaching was decreased. However, with the continuous increase in potential, the dissolution of polysul- 
fide was increased, and the $\mathrm{Cu}$ leaching was increased again. The possible reason is that some of the polysulfides on the mineral surface were oxidized and dissolved under high potential, thus the passivation was weakened.

At $400 \mathrm{mV}$, the granular intermediate produced on the chalcopyrite surface did not inhibit the chalcopyrite leaching at the initial stage. However, the dissolution of chalcopyrite was significantly inhibited when the mineral particles were almost completely covered by intermediate products due to the continuous accumulation of intermediate products. In this study, there was not enough evidence to suggest that surface jarosite was the main cause of chalcopyrite passivation.

Author Contributions: Conceptualization, X.S., W.Y. and Y.Z.; methodology, X.S.; validation, Y.Z.; formal analysis, X.S.; investigation, X.S., W.Y., K.J. and Y.Z.; resources, X.S., and Y.Z.; software, X.S.; data curation, X.S. and W.Y.; writing-original draft preparation, X.S.; writing-review and editing, X.S. and Y.Z.; supervision, Y.Z.; project administration, Y.Z.; funding acquisition, X.S. and Y.Z. All authors have read and agreed to the published version of the manuscript.

Funding: This research was funded by Project (2020zzts745) supported by the Fundamental Research Funds for the Central Universities of Central South University; National Natural Science Foundation of China (51974363).

Institutional Review Board Statement: Not applicable.

Informed Consent Statement: Not applicable.

Data Availability Statement: The data presented in this study are available on request from the corresponding author. The data are not publicly available due to the terms of the project.

Acknowledgments: We wish to thank the timely help given by Yisheng Zhang in analyzing test data and guiding manuscript revision.

Conflicts of Interest: The authors declare no conflict of interest.

\section{References}

1. Zhao, H.; Zhang, Y.; Zhang, X.; Zhang, X.; Qian, L.; Sun, M.; Yang, Y.; Zhang, Y.; Wang, J.; Kim, H.; et al. The dissolution and passivation mechanism of chalcopyrite in bioleaching: An overview. Miner. Eng. 2019, 136, 140-154. [CrossRef]

2. Linge, H.G. A study of chalcopyrite dissolution in acidic ferric nitrate by potentiometric titration. Hydrometallurgy 1976, 2, 51-64. [CrossRef]

3. Yang, Y.; Liu, W.; Chen, M. A copper and iron K-edge XANES study on chalcopyrite leached by mesophiles and moderate thermophiles. Miner. Eng. 2013, 48, 31-35. [CrossRef]

4. Dutrizac, J.E. Elemental Sulphur Formation During the Ferric Sulphate Leaching of Chalcopyrite. Can. Metall. Q. 1989, 28, 337-344. [CrossRef]

5. Klauber, C. A critical review of the surface chemistry of acidic ferric sulphate dissolution of chalcopyrite with regards to hindered dissolution. Int. J. Miner. Process. 2008, 86, 1-17. [CrossRef]

6. Antonijević, M.M.; Janković, Z.; Dimitrijević, M. Investigation of the kinetics of chalcopyrite oxidation by potassium dichromate. Hydrometallurgy 1994, 35, 187-201. [CrossRef]

7. Sandström, A.; Shchukarev, A.; Paul, J. XPS characterisation of chalcopyrite chemically and bio-leached at high and low redox potential. Miner. Eng. 2005, 18, 505-515. [CrossRef]

8. Havlik, T.; Laubertova, M.; Miskufova, A.; Kondas, J.; Vranka, F. Extraction of copper, zinc, nickel and cobalt in acid oxidative leaching of chalcopyrite at the presence of deep-sea manganese nodules as oxidant. Hydrometallurgy 2005, 77, 51-59. [CrossRef]

9. Shiers, D.W.; Collinson, D.M.; Kelly, N.J.; Watling, H.R. Copper extraction from chalcopyrite: Comparison of three non-sulfate oxidants, hypochlorous acid, sodium chlorate and potassium nitrate, with ferric sulfate. Miner. Eng. 2016, 85, 55-65. [CrossRef]

10. Hernández, P.C.; Taboada, M.E.; Herreros, O.O.; Graber, T.A.; Ghorbani, Y. Leaching of Chalcopyrite in Acidified Nitrate Using Seawater-Based Media. Minerals 2018, 8, 238. [CrossRef]

11. Sokić, M.; Marković, B.; Stanković, S.; Kamberović, Ž.; Štrbac, N.; Manojlović, V.; Petronijević, N. Kinetics of Chalcopyrite Leaching by Hydrogen Peroxide in Sulfuric Acid. Metals 2019, 9, 1173. [CrossRef]

12. Antonijević, M.M.; Janković, Z.D.; Dimitrijević, M.D. Kinetics of chalcopyrite dissolution by hydrogen peroxide in sulphuric acid. Hydrometallurgy 2004, 71, 329-334. [CrossRef]

13. Toro, N.; Pérez, K.; Saldaña, M.; Jeldres, R.I.; Jeldres, M.; Cánovas, M. Dissolution of pure chalcopyrite with manganese nodules and waste water. J. Mater. Res. Technol. 2020, 9, 798-805. [CrossRef]

14. Koleini, S.M.J.; Aghazadeh, V.; Sandström, Å. Acidic sulphate leaching of chalcopyrite concentrates in presence of pyrite. Miner. Eng. 2011, 24, 381-386. [CrossRef] 
15. Jorjani, E.; Ghahreman, A. Challenges with elemental sulfur removal during the leaching of copper and zinc sulfides, and from the residues; a review. Hydrometallurgy 2017, 171, 333-343. [CrossRef]

16. Nazari, G.; Dixon, D.G.; Dreisinger, D.B. The mechanism of chalcopyrite leaching in the presence of silver-enhanced pyrite in the Galvanox $^{\mathrm{TM}}$ process. Hydrometallurgy 2012, 113, 122-130. [CrossRef]

17. Zhao, H.; Wang, J.; Gan, X.; Hu, M.; Tao, L.; Qin, W.; Qiu, G. Role of pyrite in sulfuric acid leaching of chalcopyrite: An elimination of polysulfide by controlling redox potential. Hydrometallurgy 2016, 164, 159-165. [CrossRef]

18. Dixon, D.G.; Mayne, D.D.; Baxter, K.G. GALVANOX ${ }^{\mathrm{TM}}$-A novel galvanically-assisted atmospheric leaching technology for copper concentrates. Can. Metall. Q. 2008, 47, 327-336. [CrossRef]

19. Ghahremaninezhad, A.; Asselin, E.; Dixon, D.G. Electrochemical evaluation of the surface of chalcopyrite during dissolution in sulfuric acid solution. Electrochim. Acta 2010, 55, 5041-5056. [CrossRef]

20. Li, Y.; Wei, Z.; Qian, G.; Li, J.; Gerson, A.R. Kinetics and Mechanisms of Chalcopyrite Dissolution at Controlled Redox Potential of $750 \mathrm{mV}$ in Sulfuric Acid Solution. Minerals 2016, 6, 83. [CrossRef]

21. Zhang, Y.; Zhao, H.; Qian, L.; Sun, M.; Lv, X.; Zhang, L.; Petersen, J.; Qiu, G. A brief overview on the dissolution mechanisms of sulfide minerals in acidic sulfate environments at low temperatures: Emphasis on electrochemical cyclic voltammetry analysis. Miner. Eng. 2020, 158, 106586. [CrossRef]

22. Ahmadi, A.; Schaffie, M.; Manafi, Z.; Ranjbar, M. Electrochemical bioleaching of high grade chalcopyrite flotation concentrates in a stirred bioreactor. Hydrometallurgy 2010, 104, 99-105. [CrossRef]

23. Kametani, H.; Aoki, A. Effect of suspension potential on the oxidation rate of copper concentrate in a sulfuric acid solution. Metal. Mater. Trans. B 1985, 16, 695-705. [CrossRef]

24. Córdoba, E.M.; Muñoz, J.A.; Blázquez, M.L.; González, F.; Ballester, A. Leaching of chalcopyrite with ferric ion. Part II: Effect of redox potential. Hydrometallurgy 2008, 93, 88-96. [CrossRef]

25. Third, K.A.; Cord-ruwisch, R.; Watling, H.R. Control of the redox potential by oxygen limitation improves bacterial leaching of chalcopyrite. Biotechnol. Bioeng. 2002, 78, 433-441. [CrossRef]

26. Lotfalian, M.; Ranjbar, M.; Fazaelipoor, M.H.; Schaffie, M.; Manafi, Z. The effect of redox control on the continuous bioleaching of chalcopyrite concentrate. Miner. Eng. 2015, 81, 52-57. [CrossRef]

27. Phuong Thao, N.T.; Tsuji, S.; Jeon, S.; Park, I.; Tabelin, C.B.; Ito, M.; Hiroyoshi, N. Redox potential-dependent chalcopyrite leaching in acidic ferric chloride solutions: Leaching experiments. Hydrometallurgy 2020, 194, 105299. [CrossRef]

28. Gericke, M.; Govender, Y.; Pinches, A. Tank bioleaching of low-grade chalcopyrite concentrates using redox control. Hydrometallurgy 2010, 104, 414-419. [CrossRef]

29. Wang, J.; Gan, X.; Zhao, H.; Hu, M.; Li, K.; Qin, W.; Qiu, G. Dissolution and passivation mechanisms of chalcopyrite during bioleaching: DFT calculation, XPS and electrochemistry analysis. Miner. Eng. 2016, 98, 264-278. [CrossRef]

30. Hackl, R.P.; Dreisinger, D.B.; Peters, E.; King, J.A. Passivation of chalcopyrite during oxidative leaching in sulfate media. Hydrometallurgy 1995, 39, 25-48. [CrossRef]

31. Hiroyoshi, N.; Miki, H.; Hirajima, T.; Tsunekawa, M. Enhancement of chalcopyrite leaching by ferrous ions in acidic ferric sulfate solutions. Hydrometallurgy 2001, 60, 185-197. [CrossRef] 